\title{
A REDE SOCIAL SIGNIFICATIVA DE UMA MULHER APÓS O DIAGNÓSTICO DE HIV/AIDS $^{1}$
}

\author{
Juliana Vieira Von Zuben² \\ Maria Rosa Rodrigues Rissi \\ Carla Guanaes-Lorenzi \\ Universidade de São Paulo, Ribeirão Preto-SP, Brasil
}

\begin{abstract}
RESUMO. Partindo da concepção de que a rede social influencia a saúde de uma pessoa e de que o seu estado de saúde influencia a manutenção de sua rede, este artigo tem como objetivo compreender como se configura a rede social de uma mulher portadora do HIV/aids, considerando os sentidos produzidos acerca do impacto do diagnóstico e dos efeitos que este exerce sobre sua vida e seus relacionamentos. As informações apresentadas neste estudo foram coletadas através de entrevista individual, desenvolvida com base em um roteiro semiestruturado dividido em dois momentos: uma conversa inicial acerca do recebimento do diagnóstico de HIV/aids e uma conversa mais específica sobre a configuração da rede social significativa, após o diagnóstico, tendo como disparador a construção de um "mapa de rede". Esta entrevista foi audiogravada e transcrita na íntegra, e sua análise foi desenvolvida com base no método de estudo de caso, tendo como fundamentação as contribuições do movimento construcionista social. Nossa análise ilustra como o entrelaçamento entre 0 contexto de vulnerabilidade, o impacto do diagnóstico e os discursos em torno do HIV/aids marcam a vida de uma mulher soropositiva, influenciando a construção de sua rede social. Discutimos, assim, a importância de que o trabalho em saúde inclua uma sensibilidade relacional, com ênfase na compreensão da pessoa em rede e em contexto. Desse modo, esperamos contribuir com práticas de cuidado em saúde que visem a reduzir o impacto do diagnóstico na vida e nos relacionamentos das mulheres soropositivas (FAPESP).
\end{abstract}

Palavras-chaves: HIV; saúde da mulher; redes sociais.

\section{THE MEANINGFUL SOCIAL NETWORK OF A WOMAN AFTER THE DIAGNOSIS OF HIV/AIDS}

\begin{abstract}
Following the understanding that the social network influences one's health and that one's health influences the maintenance of their social network, this article aims to compreehend the configuration of the social network of an HIV-carrier woman, considering meanings made about the diagnosis and its effects over the woman's life and relationships. The information presented in this study was collected through an individual interview, which was developed based in a semistructured script organized in two moments: an initial conversation about the receiving of the diagnosis of HIV/aids; and a more specific conversation about the configuration of the woman's meaningful social network, which had the construction of a "network diagram" as a resource. This interview was recorded in audio and fully transcribed. The analysis of this interview was developed by the method of a case study, under the contributions of the social constructionist movement. The analysis illustrates how the context of vulnerability, the impact of the diagnosis, and the discourses surrounding HIV/aids are intertwined, impacting the life of an HIV-positive woman and influencing the construction of her social network. We discuss how important it is for healthcare work to include a relational sensibility that emphasizes an understanding of the person as a part of a network and a specific social context. Thus, we expect to contribute to healthcare practices that aim at reducing the impact of the diagnosis to the HIV-positive women lives and relationships (FAPESP).
\end{abstract}

Keywords: HIV; women's health; social networks.

\section{LA RED SOCIAL SIGNIFICATIVA DE UNA MUJER DESPUÉS DEL DIAGNÓSTICO DE VIH/SIDA}

RESUMEN. Partiendo de la concepción de que la red social afecta la salud de una persona y que su estado de salud afecta la manutención de su red, este artículo tiene como objetivo comprender como se configura la red social de una mujer portadora de $\mathrm{VIH} /$ sida, considerando los sentidos producidos acerca del impacto del diagnóstico y de los efectos que lo

\footnotetext{
${ }_{2}^{1}$ Apoio: FAPESP.

2 Endereço para correspondência: Rua Bahia, 248, Vila São Cristovão, Limeira-SP. CEP 13480-520. E-mail: ju_zuben@hotmail.com
} 
mismo ejerce sobre su vida y relacionamientos. Las informaciones presentadas en este estudio fueron colectadas a través de entrevista individual, desarrollada con base en un guión semi estructurado, organizado en dos momentos: una conversación acerca del recibimiento del diagnóstico de VIH/sida; y una conversación más específica sobre la configuración da red social significativa, después el diagnóstico, teniendo como disparador la construcción de un "mapa de red". Esta entrevista fue audio-grabada y transcrita en la íntegra, y su análisis fue desarrollado con base en el método de estudio de caso, teniendo como fundamentación las contribuciones del movimiento construccionista social. Nuestro análisis ilustra como el entrelazamiento entre el contexto de vulnerabilidad, el impacto del diagnóstico y los discursos alrededor del $\mathrm{VIH} /$ sida marcan la vida de una mujer seropositiva, influenciando en la construcción de su red social. Discutimos, así, la importancia de que el trabajo en salud incluya una sensibilidad relacional, con énfasis en la comprensión de la persona en red y en contexto. De ese modo, esperamos contribuir con prácticas de cuidado en salud dirigidos a reducir el impacto del diagnóstico en la vida y en los relacionamientos de las mujeres seropositivas (FAPESP).

Palabras clave: VIH; salud de la mujer; redes sociales.

No início da década de 1980 o mundo se viu diante de uma epidemia sobre a qual pouco se sabia, mas que atingia um número cada vez maior de pessoas e levava à morte uma grande porcentagem delas. Desde então, a busca por ações de controle, intervenção e compreensão da Síndrome da Imunodeficiência Adquirida (aids) atravessa o universo acadêmico e profissional. Os discursos sociais construídos a respeito da síndrome e dos portadores são diversos, coexistem e são negociados a todo o tempo em nossas práticas discursivas, influenciando o modo de vida e as relações dos portadores do HIV/aids.

No começo da epidemia, a situação de emergência vivenciada levou especialistas a investigarem os fatores de risco relacionados à doença, que foi associada inicialmente à homossexualidade. Com a identificação de outros casos entre usuários de drogas injetáveis, profissionais do sexo e hemofílicos, ficou configurada a primeira descrição da população atingida, conhecida como "grupos de risco" (Leão, 2005). Assim, os discursos a as ações preventivas a respeito da aids eram dirigidas a estes grupos, considerados inicialmente como expostos a maior risco de contaminação.

Conforme Miniguini e Campos (2005), esse conceito de grupo de risco, além de se mostrar ineficiente para projetar as características epidemiológicas da disseminação do HIV, acarretou importantes consequências, como reações de preconceito, estigmatização e segregação destas populações. Produziu, ainda, a percepção equivocada de que aqueles que não pertenciam aos grupos de risco estariam seguros e protegidos em relação ao HIV/aids.

Com o passar do tempo, a concepção de risco deixou de ser associada a grupos e passou a ser relacionada a comportamentos, os quais incluíam o sexo sem segurança e a troca de agulhas entre dependentes químicos. Este novo discurso diminuiu o estigma contra soropositivos, mas ainda se mostrava muito limitado, já que não apontava a responsabilidade social que a disseminação da doença demandava, enquanto a epidemia continuava atingindo grande número de pessoas (Granjeiro, Escuder, \& Castilho, 2010; Oliveira et al., 2007).

Deste modo, as limitações das ações de prevenção para grupos e comportamentos de risco se tornaram evidentes, e o discurso da culpabilização individual pelo contágio da doença foi perdendo força, assim como o discurso, implícito nestas primeiras ações, de que comportamentos saudáveis seriam resultantes de opções individuais baseadas em informações disponíveis (Tura, 1998, citado por Castanha \& Araújo, 2006).

Em decorrência das limitações destas primeiras ações, o discurso de vulnerabilidade se apresenta na atualidade como uma alternativa adequada, pois se mostra mais coerente para orientar as práticas de cuidado nesse campo. Segundo Ayres, França Júnior, Calazans e Salleti Filho (1999), "todo indivíduo é em algum grau, vulnerável à infecção pelo HIV, e isto varia ao longo do tempo em função de valores e recursos que lhe permitam ou não obter meios para se proteger" (p.57). Segundo os autores, os indivíduos infectados pelo HIV têm seu potencial de invalidez ou morte variavelmente inverso ao amparo social e à assistência à saúde de que dispuserem. Os fatores que influenciam a construção da vulnerabilidade são diversos, incluindo as dimensões cognitiva, comportamental e social.

$\mathrm{Na}$ última década a configuração da epidemia de HIV/aids tem se caracterizado pela pauperização, interiorização e feminização da doença, atingindo principalmente mulheres de baixa renda, baixa escolaridade e com pouco acesso a informações (Granjeiro et al., 2010; 
Ministério da Saúde, 2002; Silva et al., 2010), sendo a faixa etária mais atingida atualmente aquela entre 20 e 59 anos (Ministério da Saúde, 2011). Dados do Boletim Epidemiológico de DST/AIDS (Ministério da Saúde, 2011) mostram que, em 1987, a proporção de casos de HIV/aids homem-mulher era de 9,1: 1; em 2010, esta razão caiu bruscamente para 1,7:1.

Para explicar estas questões, alguns estudos partiram de um discurso cognitivo, destacando como causa desta nova configuração a falta de "percepção de risco" ou de compreensão das informações por parte das mulheres infectadas. Silveira, Béira, Horta e Tomasi (2002) e Sousa, Espírito Santo e Motta (2008), por exemplo, apontam que as mulheres participantes de seus estudos praticamente não percebiam o risco a que estavam expostas em relação à infecção, mesmo sendo consideradas como um grupo de alta vulnerabilidade.

Outros estudos enfatizaram como causa a dificuldade de negociação do uso de preservativos, método reconhecido como eficaz na prevenção da aids. Estes estudos apontam que as mulheres não o usam porque a negociação do sexo ainda tem vestígios muito fortes do papel da prostituta, porque temem introduzir desconfiança na relação ou, ainda, porque não querem desagradar seus parceiros, sendo que quando o preservativo é utilizado, ele tem o objetivo principal de evitar gravidez. Tais aspectos falam de uma situação de vulnerabilidade que se constitui de modo complexo na interface com fatores biológicos, sociais, históricos e culturais (Carvalho, Martins, \& Galvão, 2006; Carvalho \& Piccinini, 2008; Maia, Guilhem, \& Freitas, 2008; Ministério da Saúde, 2007; Silveira et al., 2002; Sousa et al., 2008).

Estudos recentes vêm discutindo a importância do amparo social como fator de proteção e enfrentamento entre pessoas que convivem com o HIV/aids (Bloom, Stewart, Johnston, Banks, \& Fobair, 2001; Carvalho, 2008; Castanha \& Araújo, 2006). De modo mais específico, pesquisadores têm destacado que o suporte social e familiar pode motivar a mulher soropositiva a continuar 0 tratamento, ou mesmo a manter sigilo sobre seu diagnóstico quando sente necessidade (Galvão \& Paiva, 2011).

Além das vivências marcadas pela experiência daqueles que vivem com HIV/Aids, muitos autores têm ressaltado a influência que as redes sociais podem exercer na vida das pessoas, em especial em situações de doença ou crises de desenvolvimento (Carvalho, 2008; Dessen \& Braz, 2000; Sluski, 1997).

Como definem Dessen e Braz (2000), o conceito de rede social é abrangente, e geralmente é referido a um sistema amplo de relações (pessoas, funções e contexto) articuladas de modo a oferecer apoio instrumental e emocional a uma pessoa em necessidade. Neste estudo adotamos a concepção de rede social significativa proposta por Sluski (1997), definida como "a soma de todas as relações que um indivíduo percebe como significativas ou define como diferenciadas da massa anônima da sociedade" (p. 41). Para o autor, a saúde de uma pessoa deve ser considerada também em função das interações microssociais (família, escola, serviços de saúde) e macrossociais (comunidade e a sociedade na qual está inserida) que fazem parte de sua vida, uma vez que estas podem interferir, de modo positivo ou negativo, nas possibilidades de enfrentamento de uma situação de crise ou adoecimento.

Como ferramenta para identificação, caracterização e compreensão da rede social significativa e de suas funções na vida de um indivíduo, Sluski (1997) propõe a construção de um "mapa de rede". Graficamente, este mapa é dividido em quatro quadrantes - família, amizades, relações de trabalho ou escolares, relações comunitárias ou de serviço - e círculos concêntricos: círculo interno das relações íntimas, círculo intermediário de relações pessoais com menor compromisso, circulo externo de conhecidos e relações ocasionais. Este mapa é construído em um exercício dialógico em que a pessoa busca definir sua rede social significativa a partir da identificação da participação de algumas pessoas em sua vida, das funções que exercem e de seus níveis de proximidade. A partir desse diálogo emerge uma narrativa em que a pessoa pode se ver inserida em uma complexa rede de relacionamentos.

Consideramos que o conceito de rede social pode ser útil para o planejamento de ações de cuidado, articulando-se a uma concepção de saúde ampliada e sensível aos seus determinantes biológicos, psicológicos e sociais. Como afirma Sluski (1997), existem evidências de que "uma rede social pessoal, estável, sensível, ativa e confiável" (p.67) pode funcionar como fator de proteção frente ao adoecimento, atuando como agente de ajuda e encaminhamento, afetando a pertinência e a rapidez da utilização de serviços de saúde, acelerando processos de cura e aumentando a 
sobrevida, ou seja, gerando saúde. Por outro lado, há indícios de que a presença de doenças de curso prolongado como o câncer, a esquizofrenia ou quadros neurológicos ou demenciais, como a doença de Alzheimer, "deteriora a qualidade da interação social e, a longo prazo, reduz o tamanho e a possibilidade de acesso a sua rede social" (p.67).

A utilização desta concepção de rede social pode contribuir para o desenvolvimento de uma visão mais complexa do indivíduo e de suas relações, auxiliando na construção de um cuidado em saúde mais sensível à importância dos significados construídos pelas pessoas sobre suas relações e ao contexto social e histórico em que estão inseridas. De modo semelhante, acreditamos que compreender possíveis modos de construção discursiva da rede social de mulheres portadoras de HIV/aids pode ser de grande auxílio para 0 desenvolvimento das práticas de cuidado nesse campo. No esforço para identificar suas redes sociais significativas, elas se envolvem em um processo de produção de sentidos sobre a vida com HIV/aids e sobre possíveis mudanças que este diagnóstico tenha trazido para suas vidas e relacionamentos, $s$ assim dialogam com os diferentes discursos sociais que têm acompanhado a produção de conhecimentos nesse campo ao longo da história.

Tendo em vista estas questões, este artigo tem como objetivo compreender como se configura a rede social de uma mulher portadora do HIV/aids, considerando os sentidos produzidos acerca do impacto do diagnóstico e dos efeitos que este exerce sobre sua vida e seus relacionamentos. De modo secundário, buscamos discutir a potencialidade do trabalho com redes sociais no planejamento de ações de cuidado à saúde da mulher soropositiva, considerando uma perspectiva ampliada e sensível ao contexto social e histórico em que se produz o processo saúde-doença.

\section{MÉTODO}

\section{Delineamento teórico-metodológico}

Esta pesquisa apresenta delineamento qualitativo e se baseia nas contribuições do movimento construcionistas social em Psicologia. De acordo com Gergen (1985), "A pesquisa construcionista social ocupa-se principalmente de explicar os processos pelos quais as pessoas descrevem, explicam, ou de alguma forma dão conta do mundo em que vivem (incluindo a si mesmas)" (p. 266). Como destacam Spink \& Medrado (2004), o foco desse tipo de investigação recai sobre a linguagem em uso, isto é, sobre como as pessoas negociam sentidos sobre o mundo em suas práticas discursivas, circunscritas a um determinado contexto social e histórico. Especialmente, adotamos a proposta de Sluski (1997) de se trabalhar a rede social significativa a partir das narrativas construídas no processo de construção desta rede. Desse modo, esse autor se aproxima de uma concepção construcionista social, reforçando que a rede social é construída pelas pessoas em suas conversas, ao darem destaque às suas relações mais significativas.

Considerando os objetivos de nosso estudo, optamos por trabalhar com o método de estudo de caso, por nos permitir uma análise particular e profunda de nosso objeto de pesquisa (Peres \& Santos, 2005). Através da análise minuciosa de uma entrevista, buscamos focalizar como alguns sentidos foram negociados na interação de uma mulher portadora do HIV/aids com a entrevistadora no exercício de construção de sua rede social. Para isso, buscamos considerar, como sugerem Spink e Menegon (2004), algumas características centrais das pesquisas qualitativas de cunho construcionista: a) a indexicabilidade reconhecimento da vinculação do sentido ao seu contexto de produção; b) a inconclusividade - a impossibilidade de controle de todas as variáveis que interferem na produção do conhecimento; e c) a reflexividade - o reconhecimento da participação do pesquisador na produção do conhecimento.

\section{Contexto, participantes e aspectos éticos}

O presente estudo é parte de uma pesquisa mais ampla, aprovada por um comitê de ética em pesquisa, a qual foi desenvolvida em um ambulatório especializado em cuidados a portadores do HIV/aids de um hospital universitário do Interior do Estado de São Paulo. Inaugurado em 1996, o serviço atende atualmente cerca de 1.400 pacientes adultos soropositivos, provenientes de 26 munícipios, que necessitam de cuidados de alta complexidade. Esta assistência é feita em diferentes níveis (ambulatório, enfermaria e hospital-dia) e conta com a atuação de uma equipe multidisciplinar composta por médicos, enfermeiros, técnicos e auxiliares de enfermagem, 
assistentes sociais, psicólogo, farmacêutico, dentista e nutricionista.

Neste artigo apresentamos a investigação desenvolvida com Mônica (nome fictício), uma mulher viúva que havia recebido o diagnóstico de HIV/aids havia cinco anos, estando desde então em tratamento ambulatorial nesse serviço. Sua entrevista foi escolhida entre outras entrevistas realizadas com o mesmo objetivo por sua riqueza de significados e por se apresentar como exemplar do que foi mais comum também na vivência das outras mulheres entrevistadas (Peres \& Santos, 2005) no que tange à construção da rede social após o diagnóstico do HIV/aids.

Este estudo se desenvolveu de modo a respeitar os aspectos éticos envolvidos em pesquisas com seres humanos. Assim, Mônica foi convidada a participar voluntariamente da pesquisa, e para isso assinou o Termo de Consentimento Livre e Esclarecido e foi devidamente orientada quanto aos seus direitos e garantia de anonimato.

\section{Procedimentos de coleta das informações}

As informações foram coletadas através de entrevista individual, desenvolvida com base em um roteiro semiestruturado dividido em dois momentos: uma conversa inicial acerca do recebimento do diagnóstico de HIV/aids, seu impacto e significados, e uma conversa mais específica sobre a configuração da rede social após o recebimento do diagnóstico, tendo como disparador a construção do "mapa de rede" proposto por Sluski (1997). A construção desse mapa foi feita conjuntamente pela entrevistadora e pela participante, buscando identificar quem seriam as pessoas significativas do convívio, localizandoas no mapa e refletindo sobre a configuração geral dessa rede. A entrevista foi realizada em uma sala de atendimento do ambulatório, no dia agendado para o retorno médico de Mônica. Para fins de registro, a entrevista foi audiogravada e transcrita integralmente, buscando-se preservar as expressões e modos de fala usados na situação de entrevista.

\section{Procedimentos de análise das informações}

A análise desenvolvida neste estudo de caso foi feita através dos seguintes passos: a) transcrição integral e literal da entrevista e sua leitura exaustiva; b) reconhecimento dos principais discursos sociais sobre HIV/aids presentificados nas práticas discursivas na situação de entrevista; e c) análise compreensiva, em que buscamos demonstrar a influência desses discursos sociais a respeito do HIV/aids sobre a narrativa construída por Mônica quanto à configuração de sua rede social significativa após 0 recebimento do diagnóstico.

\section{ANÁLISE E DISCUSSÃO DOS RESULTADOS}

No momento em que se desenvolveu a entrevista, Mônica tinha 60 anos, era viúva há oito, tinha três filhas e morava com uma delas, a mais nova, em uma pequena cidade do Interior do Estado de São Paulo. Católica não praticante, havia estudado até a $4^{\mathrm{a}}$ série e, até se descobrir portadora do HIV/aids, trabalhava junto com sua irmã como confeiteira de bolo. No momento da entrevista estava aposentada e não exercia outras atividades de trabalho.

Em relação à descoberta do diagnóstico, Mônica contou que seu corpo tinha começado a apresentar sinais estranhos, como pintas, defecação diferente, unhas mais frágeis e palidez, quando então procurou o núcleo de saúde perto de sua casa para orientação médica. Lá sugeriram que ela fizesse o exame para HIV e outras DSTs. Ela concordou, mas acreditava que o resultado seria negativo: "Eu achava que eu não tinha nada, né?"; no entanto, alguns dias após colher o exame de sangue uma agente do núcleo de saúde próximo à sua casa disse que o médico gostaria de falar com ela. Achou muito estranho e pediu que sua vizinha a acompanhasse. O médico pediu que a vizinha não entrasse na sala, mas Mônica fez questão de estar acompanhada: "Aí entramos, aí sentamos, aí ele pegou e falou, deu a notícia, né? Eu não tive reação alguma. Não chorei. Eu não fiz nada. Eu escutei". Como o médico insistia em lhe reapresentar a informação ("A senhora sabe que não tem retorno, né? A senhora sabe?"), Mônica reagiu: "Eu já escutei, não precisa falar mais! Não precisa o senhor falar mais". A notícia foi vivida como um susto, como algo completamente inesperado para esse momento de sua vida.

Logo após a notícia o médico fez seu encaminhamento para tratamento no serviço em que a entrevista foi feita. Depois de certa dificuldade em conseguir uma vaga, Mônica passou a fazer 0 acompanhamento com regularidade. Ficou três anos sem tomar medicamento, pois ainda não havia indicação para 
início de tratamento, uma vez que sua condição imunológica ainda era adequada. Depois, iniciou o tratamento medicamentoso, tendo no início bastante dificuldade em se adaptar a algum remédio, em decorrência dos efeitos colaterais, chegando a pensar em desistir. Encontrou apoio nas filhas: "Eu não escondi e elas me deram muito apoio, não se separaram de mim".

Mônica já era viúva quando foi infectada. Começou a frequentar bailes para a terceira idade com suas amigas, onde conheceu um rapaz e começaram a sair: "Eu conheci um rapaz no baile e gostei dele. Mas nunca imaginei que ele poderia ter, e também não usei preservativo, né? E ele também não me falou nada. Eu achei que ele era uma pessoa boa...".

De certo modo, a fala de Mônica retoma o estigma associado ao portador ("boas pessoas" não teriam HIV/aids). Segundo Mônica, a negociação do preservativo não foi feita pelo fato de o HIV parecer uma possibilidade distante em sua vida. Viúva, ela estava reiniciando a vivência de sua sexualidade após muitos anos da separação. O namorado era o primeiro homem com quem voltara a ter uma relação afetiva e sexual após a morte de seu marido. $\mathrm{O}$ cuidado com a prevenção parecia não caber nessa situação, por mais que já tivesse ouvido falar sobre a infecção e seus meios de prevenção.

As estatísticas atuais (Ministério da Saúde, 2011) mostram que, além do crescimento entre as mulheres, um dos grupos mais atingidos pelo HIV se encontra na faixa da terceira idade, como é o caso de Mônica. Pensamos que os discursos iniciais sobre a epidemia também têm influência sobre esta configuração e sobre a questão da prevenção: como no início ela era associada a homossexuais e a comportamentos promíscuos, pessoas como Mônica (viúva, com uma vida sexual pouco ativa) eram consideradas fora do grupo de risco e não eram incluídas nos discursos de prevenção. Assim, apesar de as concepções e discursos em torno da epidemia terem se transformado ao longo das últimas três décadas, ainda é notável a presença de resquícios dos discursos sobre grupos e comportamentos de risco nas práticas discursivas, além da inexistência de uma possível situação de vulnerabilidade e de uma baixíssima compreensão sobre ela.

Como a noção de vulnerabilidade é complexa, ela é difícil de ser evidenciada. No caso de Mônica, essa condição possivelmente constitui-se como possibilidade na articulação entre fatores cognitivos, comportamentais e sociais. Entre eles, destacamos a possível dificuldade de usar o conhecimento que possuía sobre o HIV/aids na adoção de atitudes de prevenção e a possível dificuldade de negociação do preservativo, uma vez que Mônica está inserida em uma sociedade em que ainda são acentuadas as diferenças de gênero e as expectativas de papel associadas a isto. A raiva e sentimento de traição que Mônica demonstra em relação ao ex-namorado, de certo modo, ilustra essa situação de vulnerabilidade:

\begin{abstract}
Aí um dia eu vim, passado uns meses, daí eu vim de novo no baile, aí ele tava lá e eu bati nele, eu bati nele! Eu dei na cabeça dele, chacoalhei a cabeça dele, falei assim: 'Se eu peguei foi de você! Eu não vou dar queixa porque você tem sete filhos para criar, porque senão eu ia dar queixa de você! (...) Aí sumiu da minha vida, já faz cinco anos, nunca mais tive ninguém, nunca mais me aproximei de homem nenhum. Porque eu odiei o que a gente passa...
\end{abstract}

Essa convivência entre novos e velhos discursos sobre o portador de HIV/aids aparece também na relação de Mônica com seu contexto de trabalho. Ela deixou de trabalhar por medo do preconceito: "porque eu fazia bolo de casamento, bolo... Aí eu não quis fazer mais, entendeu? Porque eu acho que as pessoas... umas não têm, mas tem as que têm preconceito da gente". Parece que Mônica viu na interrupção de seu trabalho uma forma de se proteger de possíveis preconceitos, fato que também veio a contribuir para a diminuição de sua rede social.

\section{A rede social de Mônica após o diagnóstico}

Além das mudanças no universo do trabalho e suas implicações na manutenção de sua rede social, outros aspectos da vida social de Mônica sofreram significativa alteração após o recebimento do diagnóstico. Mônica conta, por exemplo, que parou de frequentar, com suas amigas, os bailes em que conhecera o ex-namorado. Quando perguntada sobre o motivo, Mônica explicou: "Porque não veio na minha cabeça de vir mais ... Eu me arrumava bem, que nem mocinha, ... tinha um cabelo grande, até a cintura, andava com umas roupas assim bem de jovem. Eu gostava, agora não gosto mais!". Seu jeito de se vestir também mudou: "Eu passei a comprar, assim, conjunto de senhora, sabe? Calça para adulta, uma calça 
jeans, não uso mais sapato de salto." Também não se relacionou com outros homens, tendo se decepcionado com seu relacionamento anterior: "perdi o interesse, assim...".

A partir deste momento Mônica foi convidada a construir seu mapa de rede (ver figura 1), isto é, sua rede social significativa, como propõe Sluski
(1997). Foi-lhe explicada a organização do mapa em quadrantes (grupos de pessoas) e círculos (grau de proximidade) e, numa atividade conjunta com a entrevistadora, as duas fizeram o desenho e conversaram sobre as pessoas, suas funções e modos de participação em sua vida.

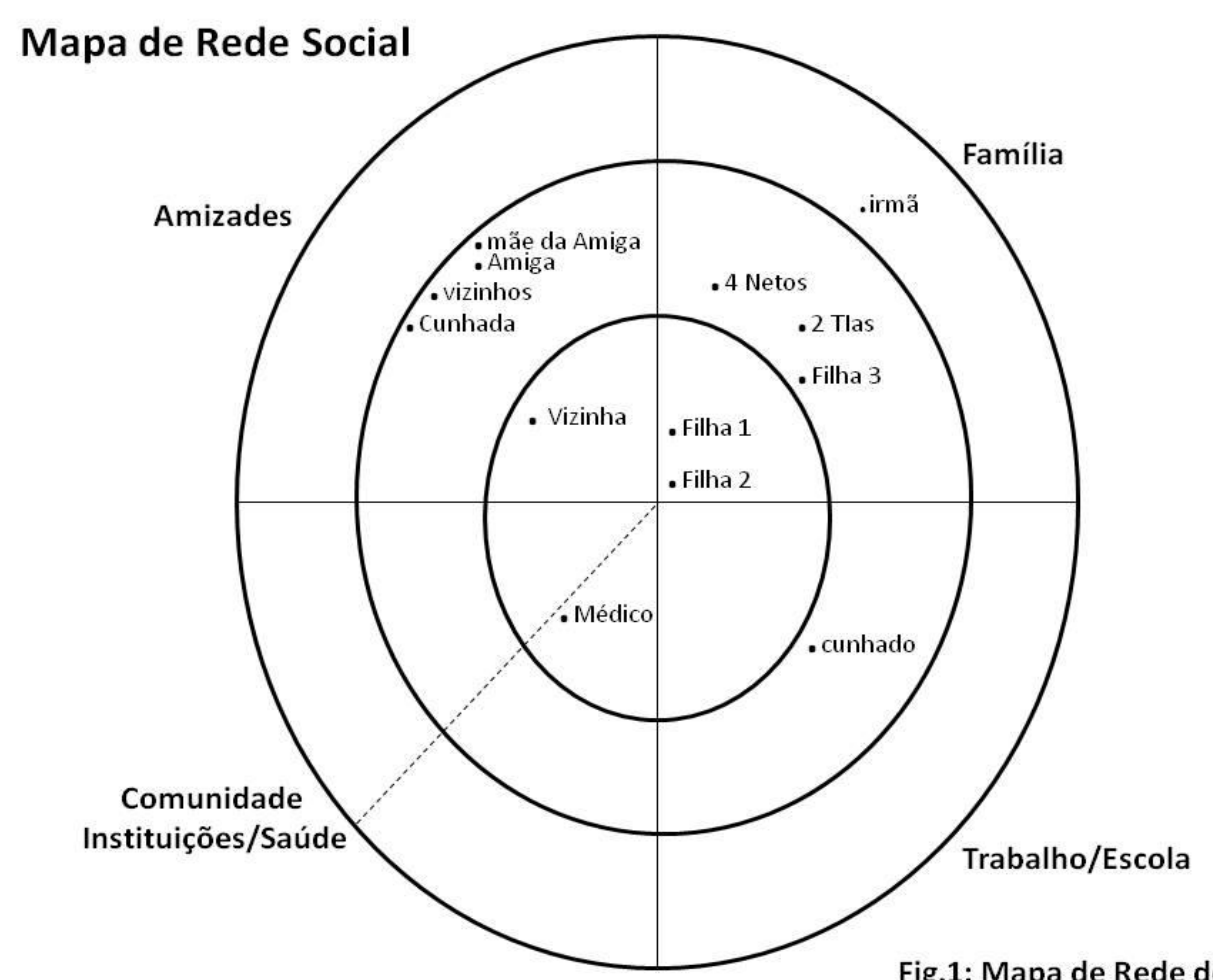

Fig.1: Mapa de Rede de Mônica

Fonte: Modelo de mapa de rede proposto por Sluski (1997).

A primeira pessoa sobre a qual Mônica falou foi sua irmã, contando sobre o afastamento entre elas. O distanciamento se deu primeiramente devido a uma briga entre as duas. A irmã discordava de sua relação com seu namorado, pois ele era negro. Depois que recebeu a notícia do diagnóstico, Mônica quis saber o que a irmã achava, genericamente, sobre um portador do HIV/aids, e a indagou de uma maneira indireta:

"Entre uma pessoa que tinha um câncer e uma com HIV, o que você faria?". E eu já sabia que eu tinha. Aí ela pegou e falou que não chegaria nem perto da pessoa que tinha HIV, porque tinha... Como que chama aquela doença antiga? Que era leproso quem tem HIV, porque essa pessoa pra ela tinha lepra. Aí eu não tive coragem de falar pra ela que eu tinha...
Esta fala remete à importância que determinados discursos sociais sobre o HIV/aids têm para a vida de Mônica, uma vez que reforçam preconceitos e estigmas. A irmã de Mônica se refere ao soropositivo como sendo equivalente a alguém com lepra, provavelmente se referindo a como os portadores de hanseníase eram vistos antigamente - como seres perigosos, depositários de forte estigma social. Observamos, neste trecho, como os discursos sociais que visam a diminuir o preconceito contra soropositivos ainda convivem, nas práticas discursivas, com aqueles que ainda associam a doença a grupos e comportamentos imorais.

Mônica conta que, apesar de ter se afastado da irmã por conta do preconceito, sente falta de uma relação mais próxima com ela. $A$ irmã é a única pessoa de sua família de origem que ainda está viva, e ela sente falta deste apoio. Como Mônica trabalhava com a irmã, este afastamento também 
resultou no seu distanciamento do cunhado, marido de sua irmã. Tal como relata, no trabalho "era minha irmã e meu cunhado, né? Que a gente passava o dia junto, ne? Ria, brincava, conversava...".

É fundamental destacar que, apesar de ser um relacionamento percebido por Mônica como distante e conflituoso, Mônica fez questão de desenhar a irmã como parte de sua rede social significativa. Em conformidade com o que aponta Sluski (1997), a rede social de uma pessoa inclui também relacionamentos que podem trazer estresse ou sofrimento. De acordo com o autor, a rede social pode gerar tanto "círculos virtuosos" nas situações em que a presença de uma rede social protege a saúde do indivíduo e a saúde do indivíduo mantém a sua rede social - como "círculos viciosos", nas situações em que a presença de uma doença afeta negativamente sua rede social, o que por sua vez terá um impacto negativo sobre a saúde do indivíduo e de sua rede social. No caso do relacionamento de Mônica com sua irmã, saber-se doente motiva seu afastamento da irmã, acentuando um conflito que, de certo modo, já existia no relacionamento entre elas.

Diferentemente, as próximas relações incluídas no mapa de Mônica foram suas três filhas e os quatro netos - aquelas significadas de modo bastante positivo. Mônica deu maior destaque à sua filha mais nova (filha 1), que mora com ela e passou a cuidar mais de sua saúde depois do diagnóstico. Esta filha tem várias funções na vida de Mônica ("ela é assim, tudo, né?"), como apoio emocional ("Ah, muito que às vezes eu desabafo, que eu choro, assim, é com essa minha filha"), cuidado com sua saúde ("é que vai comigo, que fica me olhando, se eu tô deitada no quarto, ela chega pertinho, assim, ela olha se eu tô respirando, se eu tô bem") e companhia social (Sluski, 1997).

Mônica também incluiu no quadrante da "família" duas tias que estão bem velhinhas, mas que às vezes vão visitá-la. Estas tias exercem função importante como companhia social (Sluski, 1997), aspecto importante na promoção da saúde ("elas ficam o dia inteiro lá comigo, almoçam, tomam um café, depois eu lá com elas no ponto de ônibus"); contudo, Mônica ressalta que as tias não sabem de seu diagnóstico ("Elas participam assim, só que eu acho que elas não sabem que eu tenho isso"). A não revelação do diagnóstico a estas pessoas do convívio faz com que, em alguns momentos, ela questione a legitimidade destas relações, uma vez que mantém segredo sobre algo muito importante. Assim, o sigilo sobre 0 diagnóstico vem acompanhado de certo sentimento um culpa e traição. Por outro lado, a ideia de contar o diagnóstico traz muito sofrimento, já que tem medo de seu afastamento.

Ao identificar suas relações de amizade, Mônica conta de uma única amiga, também portadora do HIV, de quem se aproximou em uma situação em que ambas confidenciaram o diagnóstico. Partiu de Mônica este primeiro passo e, a partir disso, ela se aproximou também da mãe desta moça, pela semelhança de idade entre elas ("Ela escondia de todo mundo, ela é uma pessoa reservada... Só que as pessoas comentavam, né? Aí eu me abri pra ela. E aí ela se abriu comigo, a mãe dela se abriu. E a gente se tornou amiga, né?). Elas trocam informações a respeito da doença, prevenção, cuidado com a própria saúde e com a alheia. Por exemplo, foi Mônica quem informou sua amiga sobre a importância de levar seus próprios instrumentos para as manicuras fazerem sua unha. Nessa relação, Mônica parece se posicionar como alguém que oferece ajuda, seja dando orientações seja compartilhando seu diagnóstico para ajudar a amiga a se sentir menos sozinha. A busca por construir redes de apoio entre pessoas com dificuldades semelhantes é algo bastante comum no enfrentamento de doenças crônicas, inclusive sustenta práticas que exploram este tipo de homogeneidade como recurso terapêutico. É o caso, por exemplo, dos grupos de apoio a pacientes portadores do HIV/aids (Rasera \& Japur, 2007).

Em relação a outras amizades, Mônica disse que conversa bastante com seus vizinhos ("Eu tenho bastante vizinho que eu converso, né?) e os incluiu em seu mapa de rede; mas apenas uma vizinha e sua cunhada são descritas como amizades significativas em sua vida. Neste sentido, Mônica enfatiza que sempre foi muito sociável, tendo muitos amigos e conhecidos, mas que isso mudou com o diagnóstico ("eu tenho muitas amigas assim, de vista, né, conhecida... só que é de antes, que eu não tinha nenhum problema, né? Eu era uma pessoa normal..."). A referência a si mesma como alguém que não é mais "normal", mostra como o diagnóstico de HIV/aids transformou a posição de Mônica em seus relacionamentos.

Outra pessoa importante das relações de Mônica e destacada em seu mapa foi o médico que Ihe deu o diagnóstico. Ela o colocou em sua rede, no círculo das relações mais próximas, e esta foi a única relação com profissionais da saúde descrita 
em sua rede. Ela contou que ficou muito abalada quando soube da morte dele. Essa perda deixou-a, por muito tempo, sem referências a respeito de quem poderia cuidar de sua saúde (Eu pensei: 'e agora? Agora eu não tenho mais médico!'”). Na história de Mônica, a relação próxima e afetiva com este médico (que lhe dava escuta, atenção e cuidado) foi fundamental para motivá-la a enfrentar o tratamento e dar continuidade ao cuidado à sua saúde.

Ao final da entrevista Mônica emocionou-se, dizendo que a conversa com a entrevistadora lhe trouxera lembranças de sua relação com o médico: ("De vez em quando eu choro, eu lembro do meu médico, eu choro (...) Ele tinha filho médico do lado dele, mulher médica do lado e não conseguiram segurar ele, né? Então eu falo que tudo é por Deus!'). Mônica parece, assim, refletir sobre a fragilidade e vulnerabilidade que atravessa a vida humana, atribuindo a Deus as decisões sobre doença, vida e morte...

\section{CONSIDERAÇÕES FINAIS}

Embora Sluski (1997) tenha proposto inicialmente a ideia de rede social significativa como um instrumento de trabalho da clínica, neste estudo utilizamos esta proposta como um recurso dialógico para a pesquisa. Acreditamos que a construção do mapa da rede facilitaria o diálogo em torno da influência do diagnóstico na configuração da vida e dos relacionamentos, dando visibilidade ao modo como se configurou a rede social de uma mulher após o diagnóstico de HIV/Aids. Assim, ao contrário de posturas mais tradicionais em Psicologia que descrevem o sujeito através de determinações individuais ou sociais, esta proposta de investigação adotou uma perspectiva relacional de compreensão do self, entendendo que a pessoa emerge como alguém com determinadas características que por meio dos diferentes modos se descreve e é descrita pelas pessoas nos diálogos de que participa.

A análise da entrevista com Mônica nos mostra que os discursos sociais construídos acerca da epidemia da aids em seu início, sobretudo com sua associação a grupos ou comportamentos de risco, ainda atravessam as práticas discursivas cotidianas, gerando sofrimento e isolamento social. Pelo medo do que as pessoas poderiam pensar dela ou do modo com poderia ser vista pelas pessoas de sua convivência, Mônica se antecipou, distanciando-se de alguns relacionamentos e de muitas atividades que faziam parte de sua vida. De certo modo, isso amplificou a centralidade da narrativa do HIV/aids em sua vida, diminuindo as possibilidades de, através de sua participação em outros relacionamentos, ela construir-se também de novas maneiras.

Assim, no contexto da entrevista, a narrativa construída por Mônica se mostrou "saturada pelo problema" (White \& Epston, 1990), de modo a limitar a possibilidade de descrições de si mesma fora da vivência do HIV/aids. Isso aponta a necessidade de ações voltadas à construção de um discurso corresponsável acerca do HIV/aids, que favoreça a transição dos discursos de culpabilização e responsabilização individual, para a compreensão da aids como um problema coletivo (McNamee \& Gergen, 1999).

Ao explicitar algumas nuanças presentes nesse complexo processo de configuração da rede social significativa após o diagnóstico, este estudo pôde também dar visibilidade a algumas questões já apresentadas por Sluski (1997) sobre as relações entre rede social e saúde. Se, por um lado, a rede social significativa de uma pessoa pode sofrer uma diminuição importante de tamanho em situações de adoecimento, por outro, alguns vínculos podem se fortalecer e se tornar mais íntimos e próximos. No caso de Mônica, seu relacionamento com as filhas (especialmente com a filha mais nova) se fortaleceu, ao passo que seu contato com alguns vizinhos passou a ser descrito como distante e superficial.

Especificamente quanto às contribuições para o cuidado em saúde, este estudo também permite algumas reflexões. Como fica evidente no caso de Mônica, o apoio da rede social parece fundamental para garantir uma melhor qualidade de vida e como recurso para o enfrentamento das dificuldades advindas do diagnóstico de HIV/aids, sejam estas o acometimento de outras doenças ou o preconceito social.

O processo de construção do mapa da rede social significativa e a reflexão sobre a importância das relações sociais podem ter também uma função terapêutica. O diálogo entre o profissional de saúde e o paciente em torno da configuração da rede social de um indivíduo permite dar visibilidade às relações significativas da pessoa em seu cotidiano e às funções que estas pessoas ocupam em sua vida. Além dos possíveis efeitos positivos que esse diálogo pode ter, esse tipo de prática permite fundamentar melhor outras ações terapêuticas, voltadas tanto para o próprio indivíduo 
e sua rede como para sustentação de práticas mais amplas, voltadas ao grupo dos portadores do HIV/aids como um todo. No primeiro caso, esta prática pode permitir ao profissional de saúde, por exemplo, identificar relações em que uma pessoa se encontre sobrecarregada pelas funções que exerce, possibilitando a reorganização da rede; ou também perceber situações em que 0 esvaziamento da rede coloca o indivíduo numa situação de tamanho isolamento que traz prejuízos significativos para sua saúde. No segundo caso, esta prática pode fundamentar ações voltadas à transformação dos discursos sociais acerca da aids e ao incentivo à criação de espaços grupais e de convivência em que as pessoas possam investir na reconstrução de suas redes sociais, nas situações em que estas tenham sofrido perdas significativas após o diagnóstico.

Como prática de cuidado em saúde, a atividade de construção do mapa de rede pode servir não apenas como um recurso "diagnóstico" (como foi usado nesse artigo), mas, sobretudo, como um espaço conversacional, isto é, como um recurso para pensar juntos os limites a as possibilidades da rede social construída. Nessa perspectiva, torna-se central uma escuta sensível às emoções que este processo pode mobilizar. Em nosso estudo, a construção do mapa da rede foi algo bastante mobilizador, pois deu visibilidade à ainda marcante presença do preconceito em relação à aids e, em função disso, à diminuição significativa da rede social da mulher soropostiva.

Esperamos que o nosso estudo dê visibilidade ao modo como o entrelaçamento entre o contexto de vulnerabilidade, o impacto do diagnóstico e os discursos em torno do HIV/aids marcam a vida de uma mulher soropositiva, influenciando a construção de sua rede social. Assim, esperamos contribuir para o desenvolvimento de práticas em saúde que, incluindo uma sensibilidade relacional isto é, uma sensibilidade ao entendimento da pessoa em rede e em contexto - visem reduzir o impacto do diagnóstico de HIV/aids na vida e nos relacionamentos das mulheres soropositivas.

\section{REFERÊNCIAS}

Ayres, J. R., França Júnior, I., Calazans, G., \& Salleti Filho, H. (1999). Vulnerabilidade e prevenção em tempos de aids. In R. M. Barbosa \& R. Parker (Orgs.), Sexualidades pelo avesso (pp. 49-71). Rio de Janeiro: IMS/UERJ.
Bloom J. R., Stewart, S. L., Johnston, M., Banks, P., \& Fobair, P. (2001). Sources of support and the physical and mental well-being of young women with breast cancer. Social Science \& Medicine, 53 (11), 1513-1524.

Carvalho, C. M. L., Martins, L. F. A., \& Galvão, M. T. G. (2006). Mulheres com HIV/AIDS informam conhecimento acerca da infecção. Revista de Enfermagem da UERJ, 14(3), 191-195.

Carvalho, C. S. U. (2008). A necessária atenção à família do paciente oncológico. Revista Brasileira de Cancerologia, 54 (1), 87-96.

Carvalho, F. T., \& Piccinini, C. A. (2008). Aspectos do feminino e do maternal e a infecção pelo HIV em mulheres. Ciência \& Saúde Coletiva, 13 (6), 1889-1898.

Castanha, A. R., \& Araújo, L. F. (2006). Representações sociais de agentes comunitários de saúde acerca da AIDS. Psicologia: Teoria e Prática, 8(1), 17-30.

Dessen, M. A., \& Braz, M. P. (2000). Rede social de apoio durante transições familiares decorrentes do nascimento de filhos. Psicologia: Teoria e Pesquisa, 16(3), 221-231.

Galvão, M. T. G, \& Paiva, S. S. (2011). Vivências para o enfrentamento do HIV entre mulheres infectadas pelo vírus. Revista Brasileira de Enfermagem, 64(6), 1022-1027.

Gergen, K. J. (1985). The social constructionist movement in modern psychology. American Psychologist, 40(3), 266-275.

Granjeiro, A., Escuder, M. M. L., \& Castilho, E.A. (2010). A epidemia de AIDS no Brasil e as desigualdades regionais e de oferta de serviço. Cadernos de Saúde Pública, 26(12), 2355-2367.

Leão, F. C. S. (2005). Vulnerabilidade ao adoecimento de portadores do HIVIAIDS usuários de um ambulatório especializado. Monografia de Conclusão de Curso NãoPublicada, Departamento de Ciências Humanas e Sociais, Centro Universitário de Araraquara, Araraquara.

Maia, C., Guilhem, D., \& Freitas, D. (2008). Vulnerabilidade ao HIV/Aids de pessoas heterossexuais e casadas ou em união estável. Revista de Saúde Pública, 42(2), 242-248.

McNamee, S., \& Gergen, K. J. (1999). Relational responsibility: resources for sustainable dialogue. Thousands Oaks, CA: Sage.

Miniguini, M. S., \& Campos, V. M. L. (2005). A comunicação como elemento estratégico no contexto da soropositividade para o HIV. Monografia de Conclusão de Curso NãoPublicada, Departamento de Ciências Humanas e Sociais, Centro Universitário de Araraquara, Araraquara.

Ministério da Saúde. (2002). Políticas e diretrizes de prevenção das DST/AIDS entre mulheres. Recuperado em 27 agosto, 2009, de http://bvsms.saude.gov.br/bvs/publicacoes/cd04_ 19.pdf 
Ministério da Saúde. (2007). Plano integrado de enfrentamento à feminização da epidemia de aids e outras DST. Recuperado em 20 agosto, 2009, de http://bvsms.saude.gov.br/bvs/publicacoes/plano _feminizacao_final.pdf

Ministério da Saúde. (2011). Boletim epidemiológico DST/AIDS, 7(1). Recuperado em 07 de abril de 2013

de

http://www.aids.gov.br/sites/default/files/anexos/p ublicacao/2011/50652/boletim_aids_2011_final_ m_pdf_26659.pdf

Oliveira, D. C., Formozo, G. A., Gomes, A. M. T., Acioli, S., Marques, S. C., Costa, T. L., \& Heringer, A. (2007). A produção de conhecimento sobre HIV/AIDS no campo da teoria das representações sociais em 25 anos de epidemia. Revista Eletrônica de Enfermagem, 9 (3), 821 834. Recuperado em 02 setembro, 2011, de http://www.fen.ufg.br/revista/v9/n3/v9n3a21.htm.

Peres, R.S., \& Santos, M.A. (2005). Considerações gerais e orientações práticas acerca do emprego de estudos de caso na pesquisa científica em psicologia. Interações, 10 (20), 109-126

Rasera, E.F., \& Japur, M. (2007). Grupo como construção social: aproximações entre construcionismo social e terapia de grupo. São Paulo: Vetor.

Silva, S. F. R., Pereira, M. R. P., Motta Neto, R., Ponte, M. F., Ribeiro, I. F., Costa, P. F. T. F., \& Silva, S. L. (2010). Aids no Brasil: Uma epidemia em transformação. RBAC, 42(3), 209-212.

Silveira, M. F., Béira, J. U., Horta, B. L., \& Tomasi, E. (2002). Autopercepção de vulnerabilidade às doenças sexualmente transmissíveis e Aids em mulheres. Revista de Saúde Pública, 36(6), 670677.
Sluski, C. E. (1997). A rede social na prática sistêmica: alternativas terapêuticas. (C.Berlinker, Trad). São Paulo: Casa do Psicólogo. (Original publicado em 1996).

Sousa, M. C. P., Espírito Santo, A. C. G., \& Motta, S. K. A. (2008). Gênero, vulnerabilidade das mulheres ao HIV/Aids e ações de prevenção em bairro de periferia de Teresina, Piauí, Brasil. Saúde e Sociedade, 17(2), 58-68.

Spink, M. J. P., \& Medrado, B. (2004). Produção de sentidos no cotidiano: uma abordagem teóricometodológica para análise das práticas discursivas. In M. J. P. Spink (Org.). Práticas discursivas e produção de sentidos no cotidiano: aproximações teóricas e metodológicas (pp. 41 62). São Paulo: Cortez.

Spink, M. J. P., \& Menegon, M.M. (2004). Produção de sentidos no cotidiano: uma abordagem teórico-metodológica para análise das práticas discursivas. In M. J. P. Spink (Org.). A Pesquisa como prática discursiva: superando os horrores metodológicos (pp. 63- 92). São Paulo: Cortez.

White, M., \& Epston, D. (1990). Narrative means to therapeutic ends. New York: Norton.

Recebido em 19/09/2011 Aceito em 03/05/2013

Juliana Vieira Von Zuben: graduada em Psicologia pela Universidade de São Paulo, de Ribeirão Preto, Brasil.

Maria Rosa Rodrigues Rissi: doutora em Psicologia pela Universidade de São Paulo (Ribeirão Preto-SP), psicóloga do Hospital das Clínicas da Faculdade de Medicina de Ribeirão Preto/USP e docente do Centro Universitário de Araraquara (UNIARA).

Carla Guanaes-Lorenzi: doutora em Psicologia pela Universidade de São Paulo (Ribeirão Preto-SP), docente do Departamento de Psicologia da Faculdade de Filosofia, Ciências e Letras de Ribeirão Preto (USP), atuando nos cursos de graduação e no Programa de Pós-Graduação em Psicologia, membro associado do The Taos Institute. 